\title{
IJBF DOES NOISE SIGNAL AFFECT FLIPPING ACTIVITIES?
}

\author{
Chong Fen Nee, Ruhani Ali and Zamri Ahmad \\ University Technology MARA Sarawak and \\ University Sains Malaysia
}

\begin{abstract}
In this paper, we report the explanatory power of noise signal and fundamentals on flipping activities of share trading. Flipping is defined as the percentage of opening day trading volume divided by the number of shares offered on the first trading day (Miller and Reily, 1987, and Aggarwal, 2003) in an offer for sale. It is affected by investors' opinion about, for example, the new issue's future prospect on the first listing day. The initial premium which is defined as the difference between the opening price and the offer price divided by the offer price is used as a proxy for noise signal. Using initial public offers listed on the Main Board of Bursa Malaysia during the period of 1991 to 2003, we find support for the relationship between noise signal and flipping activity in the immediate aftermarket as evident in several models tested as well as the bullish and bearish market models. Among the fundamental factors included in this study, bigger size of offer was found to discourage flipping activities.
\end{abstract}

Keywords: Initial public offers, Flipping, Traded volume, Issue size JEL Classification: G12

\section{Introduction}

There has been an increasing interest in studying investors' aftermarket trading dynamics in the Initial Public Offerings or IPO market particularly in the U.S. This emerging trend was partly attributed to the resurgence of the behavioral finance paradigm. Ellis, Michaely and O'hara (2000) documented a positive influence of initial aftermarket behaviour on initial return of new issues. There has been no study of a smaller market as of yet, and it is worthwhile to test this idea in such a market with an active new issues.

Flipping refers to the immediate sale of the new issues when the issue begins trading. Practitioners and academicians condemn flipping as a detrimental activity that depresses the early stage aftermarket performance of the new listings 
(Fishe, 2002; Aggarwal, 2003). It was believed that investors with new listings will flip either based on superior information or opening trade performance. Few have studied the implications of noise signal on flipping activities in new issues market.

From the perspective of behavioral finance theories, every person is unique and therefore, given the uncertainty on the returns from subscribing to a new issue, homogeneity of opinion is impossible. Under such a scenario, investors tend to make different estimates of expected returns from their investments. This difference in expected returns for the new issues is especially high due to the lack of track records at the time of the issue (Miller, 1977). Since behaviour is driven by expectations, and expectations are formed based on the information and noise trading information available to the investors, this study intends to study the effect of noise signal on flipping activity with ex-ante factors representing fundamental information about the issues.

An average of about 91.35 percent of the investors in Bursa Malaysian are individual investors (Bursa Malaysia Data and Research Centre, 2007), who are normally not informed investors and IPO trades are known to be based on noise (Chen, Hung and $\mathrm{Wu}, 2002$ ). Add to this a different slate of disclosures as befitting a developing market, this study of flipping activity in this market place may yield surprising results compared with the results reported for the more liquid, informed investors in that market. The Malaysian market can be classified as relatively illiquid (although not at the time of new issues) and with limited disclosures (Campos, Newell and Wilson, 2002). Indeed, the inefficiency of this market is documented by local researchers (Mat Nor, Lai and Hussin, 2002; Lai, Guru and Mat Nor, 2003; and Husni, 2005) against the efficiency evidence in Annuar et al. (1994). Hence, a study on the aftermarket trading dynamics and particularly on the effects of noise signal on flipping activity may provide modest set of results to add to the growing literature on this increasingly popular market for researchers.

The rest of this paper is organized as follows. Related literature on this topic is reviewed in the next section. Section 3 contains a description of the data and methodology commonly used for studying flipping. In section 4 , we present the empirical results to be discussed. Lastly, in section 5, a summary of the results is found as a conclusion of this study.

\section{Literature Review}

\subsection{Flipping}

Among the various immediate aftermarket activities, the investment activity of flipping new listings in the immediate aftermarket for a quick gain has become popular in studies related to aftermarket trading. Most of these studies focus on the aftermarket stabilization activities of underwriters. Underwriters in the

American market often play the role as the market maker to provide liquidity and to offset downward price pressure due to flipping particularly in if the new issue is a weak offering. 
Making quick decision under uncertainty based on noise signal has been studied by numerous researchers. The notion of 'noise' trading was introduced by Black (1986) as he asserted that noise trading is trading based on noise as if it were information. Two related studies by Delong et al. (1987) and Ritter (1991) considered noise traders as irrational traders who are extremely uncertain about future outcomes and find it hard to predict the direction of the investment returns. Due to this unpredictability of the noise trader, it is very risky for rational arbitrageurs to inhibit noise trader. Consequently, prices can diverge significantly from fundamental values: this phenomenon is well known when a crisis occurs, and noise trading increases. They contend that at times, it would be better off for the rational investors to follow and predict the guesses of the noise traders than choosing an appropriate portfolio based on fundamentals in the short-run. Later studies by Lux and Marchesi (1999) and Brown (1999) described noise traders as individual investors who do not believe in fundamental but rely on following the behaviour of others or on noise signals about trade as the primary source of information in assigning a value to an asset. Additionally, Jones' (2004) description of noise trader as small speculator with no special information also fits well with the Malaysian investors profile which are made up of uninformed individuals forming the majority who move the market.

No doubt that modern financial market depends on trading volume for their very existence. It is the trading commissions and spreads that remunerate the brokers, remisiers and other dealers. Flipping has provided liquidity to new issues in the period after the listing. However, despite this positive aspect, excessive flipping is discouraged as it is detrimental to the market performance of the new listings. In fact, the Securities Commission has imposed a moratorium (similar to "lock-up" in the U.S.) to prohibit substantial share holders who are normally the promoters of the new listings from disposing their share holdings right after the listing of the stocks as part of the effort to protect minority share holders' interest.

Nevertheless, due to the different institutional background, on top of the lock-up period imposed, underwriters in the U.S. also trade to 'stabilize' IPO initial price through various activities aimed at reducing selling pressure if severe flipping is observed. The U.S. Securities Commission allows underwriters to buy back up to an extra of 35 percent and retire the shares, as if they have never been offered before. This over-allotment option is also known as the Green Shoe Option. Ritter and Welch (2002) contended that almost all IPOs contain an overallotment option for up to 35 percent of the shares offered. This claim has been supported by Aggarwal (2000). The fear of losing market share due to excessive overpricing or underpricing of an IPO (Beatty and Ritter, 1986) could be the main motive which drives underwriters to be actively involved in stabilizing activities.

In addition to price stabilization during heavy flipping, another precautionary activity that underwriters undertake to restrict heavy flipping is by allocating more IPOs in 'strong hands' who are committed to retain the allocations rather than 'weak hands' that are likely to flip for profit shortly after the issue (Aggarwal 
and Rivoli, 1990). Normally, the 'strong hands' are allocated with IPOs via private placements. If strong hands flip, they are likely not to be included in the future initial offerings.

Using a sample of 137 IPOs take place during the period of May to July 1997, Aggarwal (2000) found that more than half the issues have short positions averaging 10.75 percent of the shares offered. A total of 22 transactions were performed over 16.6 days in the aftermarket to cover the short positions. This aftermarket price stabilization has resulted in a loss of 3.61 percent underwriting fees. She highlighted that the aftermarket activities is not transparent and underwriters manage price support activities by using a combination of aftermarket short covering to stimulate demand, penalty bids to restrict supply to flippers and the selective use of the over-allotment options. Ellis, Michaely and O'hara (2000) confirmed that lead underwriter is the dominant market maker who takes substantial inventories to support the immediate aftermarket trading.

Fishe (2002) investigated the effect of stock flipping activity and stabilization activity. He contended that in the context of American market evidence, underwriters determine the level of flipping activities and subsequent demand comes from demand with or without the flippers at the book-building stage. Underwriters then incorporate this information in pricing the issue, aiming to increase underwriting profit at the expense of flippers. Flipping activity generally lowers the level of underpricing, that is it increases the open-day price. Moreover, with a Green Shoe option, underwriters can oversell the issue and then buy back at a much lower aftermarket price particularly if it is a weak issue. Hence, in contrast to Aggarwal (2000), Fishe (2002) posits that price stabilization could actually allow the underwriter to make a profit and penalize flippers rather than merely reducing the investors' loss.

Krigman, Shaw and Womack (1999) on the other hand, examined underwriters' pricing errors and the predictive power of flipping by studying 1,232 large-cap new issues over 1988 to 1995 . They argued that flipping is not a cause of poor aftermarket performance as stated earlier, rather, it is a rational and appropriate response to unfavourable pricing. This is because new listings recorded with higher flipping activities performed worse in the long-run while those with low flipping generate abnormal return of 1.5 percent per month over the first six month after listings. Furthermore, it appears that information about the quality of issuing firms is available because large institutional investors, who are assumed to be more informed, sell issues that produce worse future performance. Therefore, underwriter's pricing errors are intentional. They also point that larger offerings recorded a higher flipping activity while initial return is negatively associated with institutional flipping activities. Flipping is measured as the percentage of sell-signed dollar volume executed in trades of 10,000 shares or more on the first trading day over the total dollar volume traded on the first day in their study.

A later study related to flipping by Aggrawal (2003), however, documented anomalous result after analyzing 617 cases during May to June 1998. She reported that hot IPO are flipped more than the cold IPO. In other words, her 
finding implies that there is a positive relationship between flipping and initial return.

A recent study on flipping activities in Australia by Bayley, Lee and Walter (2006) postulates that underpriced IPOs are flipped more than overpriced IPOs. Additionally, flipping behaviour of informed investors is unrelated to longrun returns whilst uninformed investors consistently flipped more of the IPOs with better long-run returns than their informed counterparts, the institutional investors. This claim is contradictory to that of Krigman, Shaw and Womack (1999) which showed that institutional investors flip more of the IPOs which performed worse in the long-run. However, the result of Bayley, Lee and Walter (2006) is consistent with that of Aggarwal (2003). Additionally, Bayley, Lee and Walter (2006) also report a negative relationship between firm size and flipping. Nonetheless, no relationship was found between underwriters' reputation and flipping activities.

\subsection{Noise Trading}

Noise trading models in finance suggest that some investors, especially the less sophisticated individual traders often do not make investment decisions based on fundamentals and that this group is capable of influencing stock prices by way of unpredictable changes in their sentiments. Black (1986) contended that the impact of noise on the views of the world is profound. Noise in the form of expectation need not follow rational rules. Noise do not only cause markets to be inefficient but also result in inflation. Nevertheless, noise trading plays an important role contributing to enhancing the liquid financial markets. Besides, noise trading also provides a solution to the "no-trade" theorems suggested by Milgrom and Stokey (1982).

The creation of noise trading model by Delong et al. $(1987 ; 1991)$ suggests that investor sentiments impacts stock returns and volatility. These two ideas led numerous further studies in this area. While investigating the economic consequences of noise trading, they considered noise traders as irrational traders who are extremely uncertain and it is hard to predict their actions. Moreover, with the unpredictability of noise traders' belief, it is very risky for rational arbitrageurs to inhibit noise trader. Because of this, prices can diverge significantly from fundamental. Consequently, noise traders with erroneous and stochastic beliefs could affect prices significantly and manage to earn higher returns than the rational investors. These findings have falsified the claim of EMH believers - as far as new issues market is concerned - who argue that financial markets are efficient because misinformed noise traders can have little influence on asset prices in equilibrium. In addition, they also documented that since stock prices are more volatile than can be justified based on the news of the underlying fundamentals, therefore, it would also be better off for a rational investor to predict the guesses of others than choosing the appropriate portfolio in the short run.

Lux and Marchesi (1999) divided the pool of investors into the fundamentalist and the noise traders. They defined fundamentalist as those 
who follow the premise of EMH whereby, the value of assets are equal to the discounted sum of the future earnings. Noise traders, however are investors who rely on the behaviour of others in the market as the primary source of information in assigning the value of the asset. At times, they found that the interactions between these two groups in the market drive the fundamentalists to trade more like noise traders to get short-term profit. Consistent with Lux and Marchesi (1999), Menkhoff (1998) confirmed that rational market participants use nonfundamental analyses to exploit less-rational noise traders in the German foreign exchange market.

Brown (1999) extended noise trading study to the closed-end investment funds in the U.S. market. He postulated that noise-trader theory implies a scenario whereby irrational investors acting coherently on a noisy signal as constituting the systematic risk. If noise traders affect prices then, the noisy signal is sentiment and the risk caused by noise traders is manifested as volatility. Brown (1999) found that unusual levels of individual investor sentiment are related to greater volatility of closed-ended investment funds as well. Moreover, this volatility occurs only when the market is open.

Jaggia and Thosar (2007) shed some light on the influence of noise trading in the new issues market. Their investigation on the medium-term aftermarket of high-tech U.S. issues in the late 1990s suggests that, the interplay between noise and informed trading has substantial effect on prices. Their model also indicated that behavioral variables are more vital in influencing pricing behaviour than fundamental variables.

Berkman and Koch (2007) proposed the dispersion in daily net initiated order flow across brokers as proxy for the level of noise trading in a stock. Using data from the Australian Stock Exchange, they found daily movements of the noise measure are positively associated with trading volume and market depth. Additionally, they also reported a significantly greater sensitivity of stock price to net initial order flow on Mondays.

Bloomfield, O'hara and Saar (2007) used a laboratory market to investigate the behaviour of noise traders and their impact on the stock market. They categorized participants in their experiment into three groups: (i) informed traders who possess fundamental information (ii) liquidity traders who have to trade for exogenous reasons and (iii) noise traders who do not possess fundamental information and have no exogenous reasons to trade. They found behavioral differences between liquidity and noise traders. Noise traders were found to exert positive impacts on both the volume and depth of the market. Furthermore, noise traders only adversely affect the information efficiency of the market when informed traders have very valuable private information. Finally, their finding showed that the imposition of Tobin tax to curb speculators produce no differential results between the behaviour of different groups of traders. In fact, tax reduces volume across groups.

\subsection{Fundamentals (ex-ante factors)}

Market performance is related to investors' behaviour while the knowledge about an asset in turn affects the investors' behaviour. Numerous researches 
have developed theories and models based on information asymmetry to explain performance (Ibbotson, 1975; Miller 1977; Baron, 1982; Rock 1986; Beatty and Ritter, 1986; Grinblatt and Hwang, 1989; Ritter, 1991; Welch, 1992). Pre-listing information proxing quality or ex-ante factors are proven to have predictive power over IPO performance. Since behaviour such as flipping is affected by the opinions or expectations formed after processing the information available, therefore, ex-ante factors such as operating history, market conditions, subscription ratio, underwriters' reputation and size of offer are included as control variables. These ex-ante variables also represent fundamental information as they are either published in the prospectuses or are reflections of current market situation.

\section{Data and Methodology}

The criteria adopted for sample selection are that the new listings were listed on the Main Board between 1991 and 2003 and that all information is available. Issues are only included in the sample from the Main Board as the issues therein are more or less similar in quality. Consequently, a total of 132 new issues formed the sample out of a population of 232 for this study.

The sample and required data are drawn from: Securities Commission, Bursa Malaysia Research and Data Centre, Bank Negara Malaysia and their relevant publications. The aftermarket behaviour examined in this study is flipping ratio. It is defined as the percentage of opening day trading volume divided by the number of shares offered on the first trading day (Miller and Reily, 1987 and Aggarwal, 2003). This definition is different from that of Krigman, Shaw and Womack (1999) and Houge et al. (2001) studies, where only sell-signed block volume is used.

Model 1 is developed to explore the predictive power of noise signal and ex-ante factors on flipping behaviour. It is a regression using the primary explanatory variable, namely, initial premium representing noise signal and the control variables (ex-ante factors) against the dependent variable, flipping ratio on the listing day. Since the Asian Financial Crisis which started on June, 1997 could have a significant impact on the results of Model 1, we further partitioned the sample into bullish market samples which consist of cases listed before 1 June, 1997 and bearish market sample made up of cases listed after 1 June, 1997. The new issues declined substantially due to the crisis.

Ex-ante risk factors on fundamentals in this study are well-known for their roles in affecting investor expectations and valuations in the prelisting stage. Ritter (1984) as well as Beatty and Ritter (1986) demonstrated a causal relationship between the ex-ante factors and the performance of the IPOs. Since behaviour is a function of information gauged, therefore, common proxies used for ex-ante uncertainty are: operating history, firm size, market conditions, subscription ratio and underwriter reputations. Explanations on the expected signs of the independent variables used in Model 1 are given below. 
Model 1: $\begin{aligned}(\mathrm{FR})= & \alpha-\beta_{1} \mathrm{OH}+\beta_{2} \mathrm{MktCon}+\beta_{3} \mathrm{SR}-\beta_{4} \text { LOGSizeOff }-\beta_{5} \mathrm{UR}+ \\ & \beta_{6} \mathrm{IP}+\varepsilon\end{aligned}$

Where,

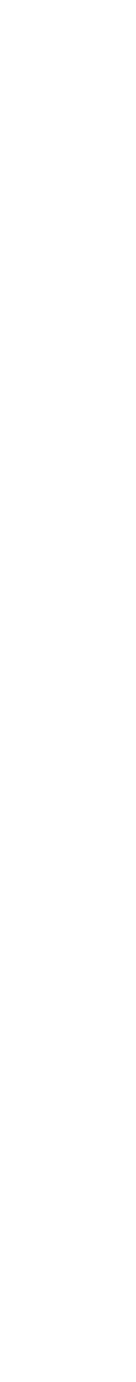

$\begin{array}{lll}\text { FR } & : & \text { Flipping Ratio, } \\ \text { OH } & : & \begin{array}{l}\text { Operating history, defined as the length of existence of } \\ \text { the company prior to IPO, }\end{array} \\ \text { MktCon } & : \quad \begin{array}{l}\text { Market Condition, the one-week average market index } \\ \text { return prior to listing, }\end{array} \\ \text { SR } & : \quad \begin{array}{l}\text { Subscription ratio, the percentage of new issues over the } \\ \text { total of new issues offered, }\end{array} \\ \text { LOGSizeOff } \quad: \quad \begin{array}{l}\text { Size of Offer, total number of shares floated times the } \\ \text { subscription price, } \\ \text { Quality of the lead underwriter; UR Dummy equals to } \\ \text { '1' for prestigious underwriter and '0' otherwise as per } \\ \text { the Bank Negara Malaysia rating, and }\end{array} \\ \text { IP } \quad: \quad \begin{array}{l}\text { Initial Premium, difference between opening price and } \\ \text { offer price divided by offer price. }\end{array}\end{array}$

From the perspective of divergence of opinion theory, a greater ex-ante uncertainty should lead to a wider divergence of opinion and hence a higher flipping activities is predicted (Miller, 1977, Miller, 2000 and Houge et al. 2001). Since ex-ante factors are indicators of uncertainty, hence, factors with higher uncertainty will have a positive relationship with flipping ratio and vice versa. Companies with longer operating history are more well established. These companies have longer track records and therefore, are presumably easier to value and hence, the uncertainties being lower. This claim has been empirically proved in studies (Beatty and Ritter, 1986; Ritter, 1984; 1991; Tay, 1993 and Klymaz, 2000). Since higher the ex-ante uncertainty is predictive of larger disagreement concerning aftermarket prices, so larger disagreement is positively associated with immediate aftermarket behaviour (Houge et al., 2001). Therefore, operating history is negatively related to flipping ratio.

Following Klymaz (2000), market condition is calculated as the average market index return prior to the first trading day. The average KLCI value one week prior to the listing date are used in this study. Some studies proved that issuers are exploiting the 'window of opportunity' while other studies suggested that IPOs are subject to 'fad' (Aggarwal and Rivoli, 1990; Ritter, 1991 and Chan, Wang and Wei, 2004). Furthermore, Ritter and Welch (2002) introduced the market timing theory which suggests that entrepreneurs are more inclined to sell shares in a bull market when investors are over-optimistic. Additional evidence on positive relationship between market conditions and level of underpricing is provided by Isa and Ahmad (1996) and Klymaz (2000). Generally, a better 
market condition is associated with a lower expected risk and hence, investors are more optimistic. With that conceptualization, a positive sign is expected from this variable.

Subscription ratio is defined as the demand of a particular new listing. Ismail, Abidin and Nasrudin (1993), Yong, Yatim and Sapian (1999), Lee, Taylor and Walter (1999) and Wan-Hussin (2002) showed that there is a positive relationship between initial return and oversubscription ratio in Malaysia and Singapore new issues markets. A higher subscription ratio reflects the confidence and the optimism that pre-IPO investors have on new issues. As such, a positive relationship is expected between subscription ratio and flipping activity.

Allen and Faulhaber (1989) as well as Welch (1989) proposed that signaling can be accomplished through the choice of underwriter. Additionally, Carter and Manaster (1990) stated that high-quality underwriters are typically associated with less underpricing. Nonetheless, Loughran and Ritter (2001) contended that new listings underwritten by high prestige underwriters during the dot-com boom in the late 1990s had higher underpricing than those managed by the less prestigious underwriters. In line with the findings from other Asian countries, Wan-Hussin (2002) found no association between underwriter reputation and IPO valuation. Since prestigious underwriters are generally associated with higher quality and less uncertain IPO. Thus, this study expects a negative relationship between prestigious underwriter and flipping activities.

Size of offer can be measured using gross proceeds of the new issues. It is a proxy for firm size. According to Ritter (1984), smaller issues are more likely to be affected by speculative forces and as a result, ex-ante uncertainty is expected to be greater for smaller firms. Nonetheless, Krigman, Shaw and Womack (1999) discovered that larger offerings recorded a higher institutional flipping. In Malaysia, consistent with Ritter (1984), Corhay, Teo and Rad (2002) discovered a negative relationship between size of offer and market return. With the conceptualization that smaller firm is subjected to higher uncertainty, therefore, a negative sign is expected for size of offer.

Initial premium is defined as the difference between the opening price and the offer price divided by the offer price. It is the first pricing indictor available on the first trading day for investors to imitate and form expectations. Hence, it also represents noise signal in this study. Since initial performance is posited to have a positive impact on flipping ratio (Krigman, Shaw and Womack, 1999), thus, a positive relationship is expected.

\section{Empirical Results and Analysis}

This section discusses the empirical results and analysis in three sub-sections. Sub-section 4.1 reports the summary statistics of the dependent variables while 4.2 contains a discussion on the correlation coefficients. Following that, in 4.3, we discuss the empirical results of the cross-sectional analyses. 


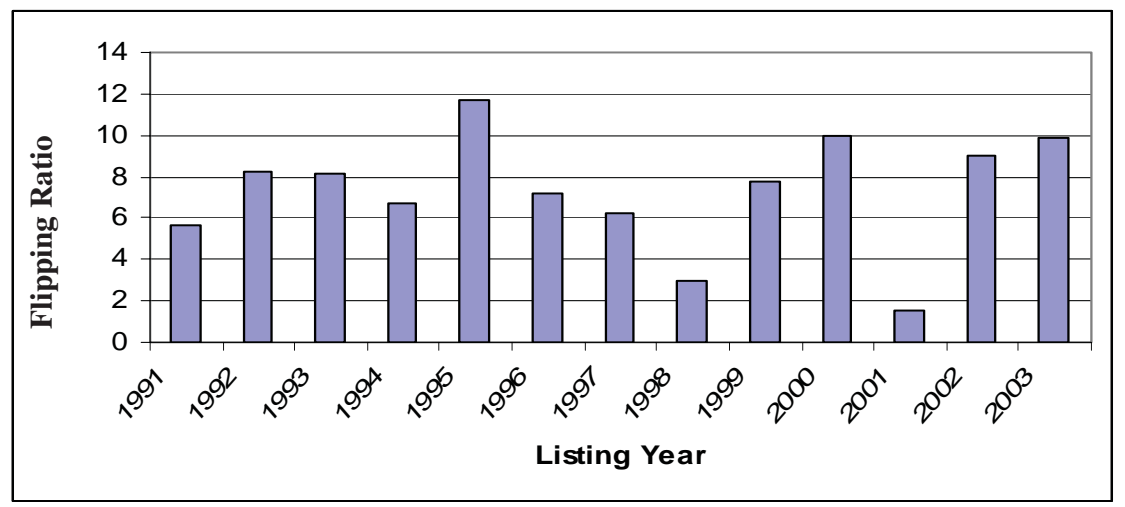

Figure 1: Summary Statistics on Flipping Ratios by Years

Figure 1 shows the average flipping ratio of investors by cohort years. Flipping ratio is defined as the percentage of opening day trading volume divided by the number of shares offered on the first trading day. Overall, flipping activities account for a rather low trading volume which ranges from 1.5 percent to 11.72 percent with an average of 7.66 percent. The moratorium imposed by the Securities Commission prohibiting substantial shareholders from disposing their shares right after the listing may have caused the low trading volume. Furthermore, the flipping ratios reported fluctuate without specific trend by cohort years. Nevertheless, the financial crisis which begins in mid-1997 as well as the post crisis till 2001 has recoded an obvious drop in flipping activities. A mean of 8.08 percent in flipping ratio is reported for the bullish market samples while an average of 6.81 percent is observed in the bearish market.

The results of Pearson correlation analysis between the variables are presented in Table 1. All the independent variables included in the model are found to be significantly related to the dependent variable and the signs are as predicted except for underwriter's reputation. Nonetheless, as discussed in the literature, the relationship between underwriter's reputation and initial return is inconclusive. Referring to Table 1, among the independent variables included in the model, some are significantly related but others are not. Since all the correlations among the independent variables are below 0.75 , multicollinearity problem is not a major concern in this study rendering it to be allowed for further testing through multiple regression procedure. (Cavana, Delahaye and Sekaran, 2001).

\subsection{Empirical Results for Cross-Sectional Analysis}

Our analysis focuses on exploring the explanatory power of the noise signal and ex-ante factors on flipping ratio. Table 2 reports the cross-sectional regression results of noise signal and ex-ante factors on flipping ratio for overall samples. Table 3 shows the cross-sectional results for the bullish market samples and lastly, Table 4 portrays the findings of the bearish market samples. 

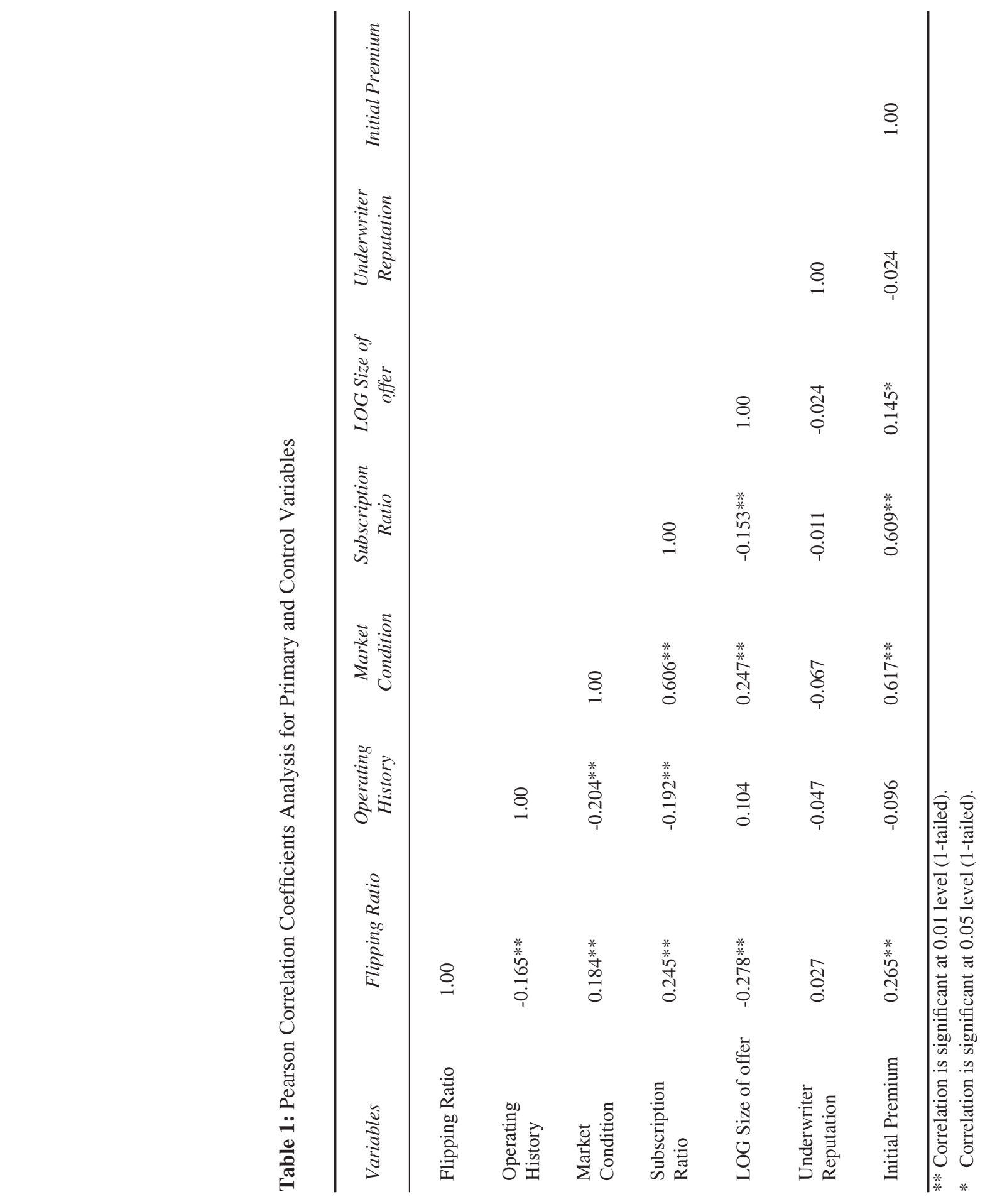
Table 2: Cross-Sectional Regression Results of Flipping Ratio, Noise Signal and Ex-ante Factors, Overall Sample

\begin{tabular}{lcc}
\hline Variable & \multicolumn{2}{c}{ Dependent Variable: Flipping Ratio } \\
\hline Independent variables & $\beta$ & $\mathrm{t}$-stat \\
& & -1.061 \\
Operating history & -0.001 & -0.182 \\
Subscription ratio & $-5.50 \mathrm{E}-005$ & 0.733 \\
Market condition & $4.93 \mathrm{E}-006$ & $-3.558^{* * *}$ \\
LOG Size of offer & -0.046 & 0.329 \\
Underwriter's reputation Dummy & 0.003 & $2.020^{* *}$ \\
Initial premium & 0.009 & \\
& & \\
F value & $4.647 * *$ & \\
$\mathrm{R}^{2}$ & 0.182 & \\
Adjusted $\mathrm{R}^{2}$ & 0.143 &
\end{tabular}

**Significant at 5\% level (one-tail test).

Results of the cross sectional regression analysis using flipping ratio as dependent variable and noise signal as well as ex-ante factors as independent variables are reported in Table 2. Overall, the model reports an adjusted $\mathrm{R}$ squared of 14.3 percent and this result is significant at the 0.05 significance level. Initial premium which is used as a proxy for noise signal is found to be a significant predictor over flipping activities. Among the fundamental proxies, LOG size of offer representing firm size is found to have significant impact on the flipping behaviour. The report of a negative relationship between firm size and flipping activity is supported as in Bayley, Lee and Walter (2006).

The model has a good fit with a significant F-ratio of 4.647. The explained variation as judged by adjusted R-squared value is small, 14.3 percent. Thus, this model appear to provide support for flipping activities in the Bursa Malaysia.

The Asian financial crisis has affected the performance of the share market. After the commencement of the financial crisis, the share market has been in a bearish mode for a considerable time. Hence, to get a better feel for the effect of the crisis on flipping activity, we partitioned the sample into the bull and bear market samples using 1 June, 1997 as the cut-off point. The result was 87 cases were listed before the cut-off date under bullish market condition; 45 cases under the bearish market condition. Referring to the statistics in Table 3, which reports results of the cross-sectional analysis for bullish market samples, it is found that investors flipping activity is significantly affected by noise signal.

Nevertheless, none of the ex-ante factors included in the analysis is having any explanatory power for flipping activities. This is consistent with noise trading in a bullish period in that during a bull market, prices are going up, and the behaviour is to flip more to get higher return than is possible based on fundamentals alone. The model fit is significant and the R-squared value is very low, 11 percent. 
Table 3: Cross-Sectional Regression Results of Flipping Ratio, Noise Signal and Ex-ante Factors for Bullish Market Samples

\begin{tabular}{|c|c|c|c|}
\hline Variable & \multicolumn{3}{|c|}{ Dependent Variable: Flipping Ratio } \\
\hline Independent variables & & $\beta$ & $t$-stat \\
\hline Operating history & & -0.001 & -0.894 \\
\hline Subscription ratio & & $5.88 \mathrm{E}-006$ & 0.017 \\
\hline Market condition & & $5.62 \mathrm{E}-006$ & 0.190 \\
\hline LOG Size of offer & & -0.032 & -1.813 \\
\hline Underwriter's reputation Dummy & & -0.003 & -0.197 \\
\hline Initial premium & & 0.008 & $1.981 * *$ \\
\hline F value & $4.647 * *$ & & \\
\hline $\mathrm{R}^{2}$ & 0.182 & & \\
\hline Adjusted $\mathrm{R}^{2}$ & 0.143 & & \\
\hline
\end{tabular}

**Significant at 5\% level (one-tail test).

Table 4: Cross-Sectional Regression Results of Flipping Ratio, Noise Signal and Ex-ante Factors for Bearish Market Samples

\begin{tabular}{|c|c|c|}
\hline \multirow{2}{*}{$\begin{array}{l}\text { Variable } \\
\text { Independent variables }\end{array}$} & \multicolumn{2}{|c|}{ Dependent Variable: Flipping Ratio } \\
\hline & $\beta$ & $\mathrm{t}$-stat \\
\hline Operating history & -0.001 & -0.857 \\
\hline Subscription ratio & 0.002 & 1.600 \\
\hline Market condition & 5.04E-005 & 0.627 \\
\hline LOG Size of offer & -0.043 & $-2.047 * *$ \\
\hline Underwriter's reputation Dummy & 0.006 & 0.330 \\
\hline Initial premium & 0.023 & $1.995 * *$ \\
\hline F value & $4.649 * *$ & \\
\hline $\mathrm{R}^{2}$ & 0.430 & \\
\hline Adjusted $\mathrm{R}^{2}$ & 0.337 & \\
\hline
\end{tabular}

**Significant at 5\% level (one-tail test).

Cross-sectional regression results of noise signal and ex-ante factors on flipping ratio for the bearish market sample is presented in Table 4. Findings show that the bearish market model is significant with an F value of 4.649 and 
an adjusted R-squared of 33.7 percent. Consistent with the bullish market model, initial premium proxing noise signal is found to have a significant influence on the flipping activities in the period after the crisis had hit. The only ex-ante factor which can significantly explain flipping activity of the bearish market is LOG size of offer. Consistent with the results on the overall sample, a bigger size of offer is found to discourage flipping activities when the market is bearish. These results are also in accord with common sense, and the prior literature on developed markets such as the U.S. and Austalia.

\section{Summary and Conclusion}

Cross-sectional regression analysis using flipping ratio as dependent variable, initial premium as primary explanatory variable representing noise signal and the ex-ante factors proxying fundamentals found that the model is significant. Test results show that independent variables included are able to explain 14.3 percent of the variations in flipping activities during the first listing day; 11 percent during bullish market and 33.7 percent during bearish market conditions. Initial premium representing noise signal was found to have a significant positive influence on the investors' decisions to flip a particular IPO on the listing day. Among the proxies for fundamental factors, LOG size of offer as company size is identified to be a significant predictor over flipping activities.

Similar analyses done on the bullish and bearish market samples uncovered that investors' flipping behaviour is significantly associated to noise signal regardless of the market conditions. None of the ex-ante factors representing fundamentals is found to have an influence on the bullish market model. On the other hand, in line with the finding provided by the overall sample, investors' flipping behaviour is found to be significantly influenced by size of offer that represents.

In conclusion, this paper has presented some new findings on how noise signal and ex-ante risks factors affect the investor behaviour described as flipping. Additionally, it also provides evidence on the relative importance of each ex-ante factors in predicting flipping activity on the first listing day. This is to our knowledge a first study to report evidence of flipping behaviour in an emerging market. That behaviour appears to be slightly different in bearish and bullish market conditions. To generalize these findings to other markets, more publications on few more emerging markets is necessary.

Author statement: The submitting author is a lecturer in the Faculty of Business Management, UiTM, Kampus Kota Samarahan, Jalan Meranek, 94300 Kota Samarahan, Sarawak Malaysia. E-mail: wuinee@pd.jaring.my. The co-authors are respectively Ruhani Ali, Professor, and Zamri Ahmad, at the University Sains Malaysia: The authors express their thanks to the extensive editing of the paper by the Editors of the journal following the review process. The authors alone are responsible for any errors. 


\section{References}

Aggarwal,R., and Rivoli,P.(1990).FadsinIPOmarket?FinancialManagement,19, $45-57$.

Aggarwal, R., and Rivoli, P. (2000). Stabilization activities by underwriters after initial public offerings. The Journal of Finance, LV (3), 1075-1103.

Aggarwal, R., and Rivoli, P. (2003). Allocation of initial public offerings and flipping activity. Journal of Financial Economics, 68, 111-135.

Allen, F., and Faulhaber, G. (1989). Signalling by underpricing in the IPO Market. Journal of Financial Economics, 23, 303 - 323.

Annuar, M.N., Ariff, M., and Shamsher M. (1994). Is Kuala Lumpur's emerging share market efficient? Journal of International Financial Markets, Institutions \& Money, 4(1), 89-100.

Baron, D. (1982). A model of the demand for investment banking advising and distribution services for new issues. The Journal of Finance, 37(4), 955976.

Bayley, L., Lee, P., and Walter, T.S. (2006) IPO flipping in Australia: Crosssectional explanations. Pacific-Basin Finance Journal, 14, 327-348.

Beatty, R.P., and Ritter, J.R. (1986). Investment banking, reputation and the underpricing of Initial Public Offerings. Journal of Financial Economics, $15,213-232$.

Berkman, H., and Koch, P.D. (2007). Noise trading and the price formation process. Journal of Empirical Finance.

Black, F. (1986). Noise. The Journal of Finance, 41(3), 529 -543.

Bloomfield, R., O'Hara, M., and Saar, G. (2007). How noise trading affects markets: An experimental analysis. Retrieved from http://www.ssrn.com.

Brown, G.W. (1999). Volatility, sentiment and noise traders. Financial Analysts Journal, 82-90.

Bursa Malaysia Research and Data Centre. (2007). Data on investors' profile. Kuala Lumpur: Bursa Malaysia.

Carter, R., and Manaster, S. (1990). Initial public offerings and underwriter reputations. The Journal of Finance, 45(4), 1045-1067.

Cavana, R.Y., Delahaye, B. I., and Sekaran, U. (2001). Applied business research: Qualitative and quantitative methods. New York: John Wiley $\&$ Sons. Inc.

Chan, K., Wang, J., and Wei, K.C. (2004). Underpricing and long-term performance of IPOs in China. Journal of Corporate Finance, 10, 409 $-430$

Chen, A., Hung, C.C., and Wu, C.S. (2002). The underpricing and excess returns of initial public offerings in Taiwan based on noisy trading: A stochastic frontier model: Review of Qualitative Finance and Accounting, 18(2), $139-158$.

Campos, C.E., Newell, R.E., and Wilson, G. (2002). Corporate governance develops in emerging markets. Retrieved from http: www.srrn.com 
Corhay, A., Teo, S., and Rad, A. (2002). The long run performance of Malaysian Initial Public Offerings: Value and growth effects. Managerial Finance, 28(2), 52-65.

Delong, B. J., Shleifer, A., Summers, L. H., and Waldmann, R. (1987). The economic consequences of noise traders. Working Paper (No. w2395). National Bureau of Economic Research (NBER), Harvard University.

Delong, B. J., Shleifer, A., Summers, L. H., and Waldmann, R. (1991). The survival of noise traders in financial market. Journal of Business, 64,119.

Ellis, K., Michaely, R., and O'hara, M. (2000). When the underwriter is the market maker: An examination of trading in the IPO aftermarket. The Journal of Finance, LV (3), 1039-1074.

Fishe, R.P.H. (2002). How stock flippers affect IPO pricing and stabilization. Journal of Financial and Quantitative Analysis, 37(2), 319-340.

Grinblatt, M., and Hwang C.Y. (1989). Signalling and pricing of new issues. The Journal of Finance, 44(2), 393-420.

Houge, T. (2001). Divergence of opinion, uncertainty and the quality of initial public offerings. Financial Management, 30(4), 5-23.

Husni, T. (2005). Price randomness, contrarians and momentum strategies: A study of return predictability in the Malaysian stock exchange (Doctoral dissertation Universiti Sains Malaysia, 1990).

Ibbotson, R.G. (1975). Price performance of common stock new issues. Journal of Financial Economics, 2, 235-272.

Isa, M., and Ahmad, R. (1996). Performance of new issues on the Malaysia stock market, Malaysia, Journal of Economic Studies, 13(2), 53-66.

Ismail K., Abidin, F., and Nasruddin, Z. (1993). Performance of new stock issues on the KLSE. Capital Market Review, 1(1), 81-95.

Jaggia, S., and Thosar, S. (2007). The medium-term aftermarket in hightech IPOs: Patterns and implications. Journal of Banking and Finance (Forthcoming).

Jones, D. (2004). Noise traders, a brief review. Retrieved from http://www. CISCO futures.com

Klymaz, H. (2000). The initial and aftermarket performance of IPOs in an emerging market: Evidence from Istanbul stock exchange. Journal of Multinational Financial Management, 2(2), 213-227.

Krigman, L., Shaw, W., and Womack, K. (1999). The persistence of IPO mispricing and the predictive power of flipping. The Journal of Finance, 54(3), 1015-1044.

Kuala Lumpur Stock Exchange, Listing Statistics. Retrieved from http://www. bursamalaysia.com

Lai, M.M., Guru, K., and Mat Nor, F. (2003). Do Malaysian investors overreact? Journal of American Academy of Business, 2(2), 602-609.

Lee, P.J, Taylor, S.L., and Walter T, S. (1996). Expected and realised returns for Singaporean IPOs: Initial and long-run analysis. Pacific-Basin Finance Journal, 4(1-2), 153-180. 
Loughran, T., and Ritter, J. R. (2001). Why has IPO underpricing increased over time? (Working Paper). University of Florida.

Loughran, T., and Ritter, J. R. (2004). Why has IPO underpricing changed over time? Financial Management, 33(3), 5-38.

Lux, T., and Marchesi, M. (1999). Scaling and criticality in a stochastic multiagent model of a financial market. Nature, 397, 498-500.

Mat-Nor, F., Lai, M.M., and Hussin, A. M. (2002). Price randomness, fundamental factors, and stock market contrarian Strategy: Further evidence on Malaysian stock market. Proceedings of the 4th Malaysian Finance Association. Malaysia: Penang.

Menkhoff, L. (1998). The noise trading approach - questionnaire evidence from foreign exchange. Journal of International Money and Finance, 17, 547567.

Milgrom, P., and Stokey, N. (1982). Information, trade and common knowledge. Journal of Economy Theory, 26, 7-27.

Miller, E. (1977). Risk, uncertainty and divergence of opinion. The Journal of Finance, 32(4), 1151-1168.

Miller, E. (2000). Equilibrium with divergence of opinion. Review of Financial Economics, 9, 27-41.

Miller, R. E., and Reilly, F. K. (1987). An examination of mispricing, returns, and uncertainty for initial public offerings. Financial Management, 16, 33-38.

Ritter, J. F. (1984). The hot issue market of 1980. The Journal of Business, 57(2), 215-240.

Ritter, J. R. (1991). The long-run performance of initial public offerings. The Journal of Finance, XLVI (1), 3-27.

Ritter J. R., and Welch, I. (2002). A review of IPO activity, pricing and allocation. Journal of Finance, 57(4), 1795-1829.

Rock, K. (1986). Why new issues are underpriced? Journal of Financial Economics, 15, 187-212.

Tay, S.W. (1993). The long run performance of initial public offerings in Malaysia. Capital Markets Review, 1, 61-80.

Wan-Hussin, W.N. (2002). Investor protection mechanism and IPO valuation on the Kuala Lumpur Stock Exchange. Retrieved from http://www.ssrn. com

Welch I. (1989). Seasoned offerings, imitation costs, and the underpricing of initial public offerings. The Journal of Finance, 44(2), 421-449.

Welch, I. (1992). Sequential sales, learning and cascades. The Journal of Finance, 47, 695 - 732

Yong, O., Yatim, P., and Sapian, R. Z. (1999). Significance of board of listing and type of issue on the under-pricing and after-market performance of Malaysian IPOs. Capital Market Review, 7(1) \& (2), 47-74. 


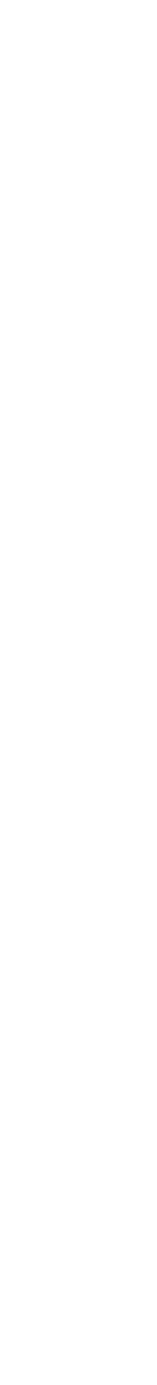

